\title{
Études/Inuit/Studies
}

\section{Hommage familial}

\section{Yanaël Plumet}

Volume 39, numéro 2, 2015

URI : https://id.erudit.org/iderudit/1038153ar

DOI : https://doi.org/10.7202/1038153ar

Aller au sommaire du numéro

\section{Éditeur(s)}

Centre interuniversitaire d'études et de recherches autochtones (CIÉRA)

\section{ISSN}

0701-1008 (imprimé)

1708-5268 (numérique)

Découvrir la revue

Citer ce document

Plumet, Y. (2015). Hommage familial. Études/Inuit/Studies, 39(2), 305-306.

https://doi.org/10.7202/1038153ar d'utilisation que vous pouvez consulter en ligne.

https://apropos.erudit.org/fr/usagers/politique-dutilisation/ 


\section{Hommages à Patrick Plumet}

\section{Hommage familial}

Pour commencer, j' aimerais remercier chaleureusement Yves Labrèche pour cette initiative qui est la sienne d'avoir proposé d'inclure dans ce congrès d'Études inuit quelques séances en hommage à mon père Patrick Plumet et au travail qu'il a accompli durant près de 40 ans de recherches menées au cœur de l'archéologie arctique. Un sincère merci également à Murielle Nagy et à l'équipe de la revue Études/Inuit/Studies qui ont permis à cette initiative de prendre forme au sein de ce congrès. Merci tout d'abord parce que cela nous touche, nous, sa famille présente aujourd'hui, ma mère, mon frère et moi-même, de sentir qu'au travers de votre communauté scientifique ce travail continue de porter ses fruits et de participer au tissage des connaissances actuelles en alimentant les échanges entre les différents professionnels animés par le sujet. Merci encore parce que cela a été l'occasion de nous pencher sur la question et d'ouvrir les deux premiers tomes de son dernier livre et de nous y aventurer en tant que lecteurs néophytes, un peu désarmés par notre manque de connaissance en la matière, mais motivés par l'échéance de ce rendez-vous avec vous.

Il nous reste à chacun encore plusieurs chapitres à parcourir, mais cet événement déclencheur nous a quand même permis de mesurer l'étendue des terrains couverts, de comprendre un peu la nature des questions posées par ses recherches et d'apprécier l'ensemble des liens établis entre les différentes disciplines. Et, surtout, cela nous a permis de nous rapprocher a postériori du chercheur et du scientifique chez qui l'engagement passionné qu'il vouait à son travail était indissociable du père ou du mari qu'il était.

Si la sphère professionnelle a toujours tenu une place très importante dans la vie de Patrick, il a saisi les occasions, quand cela était possible, d'inclure sa famille dans les différents périples liés à ses missions. La première initiative, ayant laissé une jolie trace cinématographique, fut la réalisation du documentaire Poutoulik chez les Inuits en 1974, où toute la famille partit pour l'île d'Akpatok en s'intégrant à la vie du camp de fouilles et aux différentes missions. Il y eut aussi le Kenya, en 1986, où l'invitation faite à Patrick de venir visiter des sites fut l'occasion d'un très beau périple familial. Parfois, à l'inverse, c'étaient les voyages de vacances en famille qui prenaient tournure de repérages archéologiques où chaque petit tas de cailloux suspect prenait valeur de monument historique et suscitait de longs commentaires didactiques en les passant à l'incontournable crible photographique. Il y eut ainsi un magnifique voyage en 1982 en Algérie, dans le désert du Tassili, avec la découverte de peintures rupestres, ou encore 
un séjour en Écosse où on répertoria, je pense, le moindre cairn apparent, pour ne citer que quelques exemples.

J'ai souvent entendu Patrick dire que son implication dans l'archéologie tenait du hasard ou d'un concours de circonstances qui lui avait procuré des conditions favorables pour satisfaire méthodiquement sa curiosité pour l'humain, son goût pour la recherche et le voyage. Ce concours de circonstances, dans lequel nous aimerions souligner l'influence importante de Louis-Edmond Hamelin, qui lui ouvrit les premières portes au Québec à la fin des années 1960 et qui signa la préface de son livre presque 40 ans plus tard, l'aura amené à diriger durant 30 ans le laboratoire d'archéologie de l'UAQM. Trente ans à faire passer à travers la moulinette minutieuse des fouilles, des relevés et analyses, puis de nombreuses publications, l'ensemble des questions et des fragments de réponses sur l'origine des premiers peuplements du continent américain et les mystérieuses lignées des peuples du Grand Nord dans leur fascinant environnement arctique.

Ces questionnements et ces fragments de réponses qu'il avait le souci d'actualiser jusqu'au dernier moment auront largement occupé ses années de retraite en faisant l'objet de la publication des deux premiers tomes de son livre Peuples du Grand Nord. Le troisième et dernier tome de ce livre, qui je pense devait ouvrir sur la dimension plus globale et résolument actuelle de ses recherches, était sur le point de trouver sa version finale peu de temps avant son départ. Nous avons l'espoir, avec le concours de son éditeur et de l'archéologue Claire Alix, d'amener ce dernier tome jusqu'à la publication.

Peut-être face aux troubles sévères et crises diverses que traverse notre époque, j'ai aussi entendu Patrick exprimer ses doutes quant à la nécessité pragmatique ou l'intérêt véritable pour la collectivité humaine de ces plongées dans les vestiges des origines de notre espèce. L'important, je crois, était son insatiable curiosité et cette dynamique intellectuelle qui l'habitait pour rassembler et mettre en lien les nombreux domaines qui l'intéressaient. Si le hasard lui a donné pour prisme l'archéologie arctique, comme point d'orgue à l'ensemble de ses recherches, c'est bien finalement les éternels questionnements de l'humain qui étaient sous-jacentes et en ligne de mire: d'où venons nous, qui sommes nous, où allons nous?

Je ne pense pas que nous apporterons aujourd'hui une réponse exhaustive à ces questions, mais j'aimerais profiter de cette occasion pour simplement vous remercier d'avoir participé chacun à votre manière, par les relations que vous entreteniez avec Patrick, à leur élaboration et à leur formulation, comme un gage d'humanité et de culture. 